\title{
Perfil dos autores de letalidade violenta no município do Rio de Janeiro, Brasil (2015)
}

\author{
Profile of Rio de Janeiro's violent lethality perpetrators, Brazil \\ (2015)
}

${ }^{1}$ Fundação Oswaldo Cruz, Departamento de Estudos Sobre Violência e Saúde Jorge Careli - CLAVES. Av. Brasil 4.036, sala 700, Manguinhos. 21040-361 Rio de Janeiro RJ Brasil. maminayo@terra.com.br

\begin{abstract}
This study presents the profile of the perpetrators of deaths caused by intentional aggressions in Rio de Janeiro, Brazil, in 2015, as per data from the State Civil Police (PCERJ) investigations. This is a quantitative, descriptive, and cross-sectional study. The information encompasses "premeditated murder", "larceny", "bodily injury followed by death" and "homicide caused by resisting police intervention". The study analyzes the profile of the authors of each category, except homicides committed by police intervention. The crimes committed by police intervention were excluded from the total number of the 1,562 identified deaths. Only about 20\% of the perpetrators of the 1,255 crimes investigated were identified. The data recognized show the relevance of drug traffickers and militiamen illegal activities in the deaths and interpersonal violence in domestic and community spaces and neighborhoods. A remarkable similarity is observed between the profile of violent lethality perpetrators and victims in the studied urban contexts: men, young people, and young adults aged 19-39 years, blacks, with low schooling, high levels of unemployment, and informal occupations.
\end{abstract}

Key words Social violence, Perpetrators, Violent lethality
Resumo Apresenta-se o perfil dos autores de mortes por agressões intencionais no município do Rio de Janeiro, em 2015, segundo dados de investigação da Polícia Civil do Estado (PCERJ) sobre letalidade violenta. É um estudo quantitativo descritivo e transversal. As informações englobam homicídios dolosos, roubo seguido de morte, lesões corporais seguidas de morte e homicídios provenientes de oposição à intervenção policial. Do total de 1.562 mortes, subtraíram-se as cometidas por intervenção policial. Dos 1.255 crimes estudados, apenas 20\% tiveram os autores identificados. Demonstra-se a significancia das atividades ilegais de traficantes de drogas e milicianos nas mortes. Mas também a da violência interpessoal nos espaços domésticos e de convivência e vizinhança. Existe grande semelhança entre o perfil dos autores e das vitimas de letalidade violenta no contexto urbano estudado: homens, jovens e adultos jovens entre 19 e 39 anos, negros e pardos, com baixa escolaridade e elevados níveis de desemprego e ocupação informal.

Palavras-chave Violência social, Agressores, Letalidade violenta 


\section{Introdução}

O objetivo deste trabalho é contribuir para o conhecimento do perfil dos agressores de letalidade violenta no município do Rio de Janeiro e fazer uma análise da relação entre eles e as vítimas, tomando como base o ano de 2015. O período escolhido está de acordo com a metodologia adotada pelo sistema de segurança pública do Estado, que estabelece o mínimo de 24 meses como parâmetro razoável para elucidação dos homicídios. Como a pesquisa que dá origem a este trabalho se iniciou em 2017, os dados disponíveis se limitaram a 2015. A escolha da abordagem se baseou na hipótese de que esse procedimento seria capaz de evidenciar o perfil do autor da letalidade violenta, definida pelas autoridades policiais como "morte decorrente de ação intencional", reunindo: roubo seguido de morte (latrocínio); homicídio proveniente de oposição à intervenção policial; lesão corporal seguida de morte e homicídio doloso. Embora numérica e proporcionalmente sejam aqui contabilizadas as quatro tipologias de crime que compõem o conceito, apenas três são aprofundadas. As mortes decorrentes do exercício da atividade de agentes de segurança pública, por conterem especificidades não comparáveis com as outras, serão tratadas em outra oportunidade.

Os autores dos três primeiros tipos referidos de letalidade violenta constituem o objeto central do trabalho, tendo em vista a relevância que as mortes por agressão têm no mundo ${ }^{1,2}$, no Brasil ${ }^{3,4}$ e no Rio de Janeiro ${ }^{5,6}$. Por ser o evento mais grave na categorização da violência, os homicídios são um indicador universal desse fenômeno ${ }^{1}$, permitindo comparações entre países e internamente. Neste estudo, seu sentido está restrito às agressões realizadas por um ou mais autores contra outras pessoas, nos mais diversos contextos e motivações que culminaram na morte da vítima, ensejando o procedimento de investigação da polícia civil para definir autoria e circunstâncias ${ }^{5,6}$.

O município do Rio de Janeiro registrou 18,5 homicídios dolosos por 100 mil habitantes em 2015, a menor taxa dos últimos 25 anos. Esse tipo de letalidade apresentou queda de $15,1 \%$ também no estado (taxa de 25,4/100.000) no mesmo período, a segunda menor registrada em toda a série histórica iniciada em $1991^{6-8 .}$ Conjunturalmente, no município e no estado, em 2015 vivia-se o último período da proposta de Unidades de Polícia Pacificadora (UPP), que independentemente do juízo que se faça delas, conseguiram estancar o excessivo número de mortes nesse espaço social ${ }^{9}$.

A literatura acerca da letalidade violenta, tanto a do campo da saúde pública quanto a das ciências sociais, em geral se ocupa das mortes intencionais sob a ótica da vítima. Os trabalhos conduzem ao detalhamento de um perfil amplamente difundido de grupos vulneráveis, integrados por homens jovens, negros, pertencentes às camadas mais empobrecidas, residentes das periferias dos centros urbanos ${ }^{10-17}$.

Quando se olha para os homicídios pelo prisma de quem comete a agressão, obtém-se muito pouco retorno da literatura científica brasileira. Em geral, os artigos se restringem a nichos muito específicos, como adolescentes infratores, agressores de mulheres e autores de homicídio seguido por suicídio ${ }^{17-19}$. Dos poucos trabalhos que consideram agressor e vítima estão os de Duque e colaboradores $^{20}$ e de Minayo e Constantino ${ }^{21}$. O último analisa o ecossistema desse fenômeno dentro de um espaço sociogeográfico, definido em suas estruturas e elementos de interação, cercado por um ambiente externo que ao mesmo tempo se diferencia dele e reconhece sua especificidade. Acoplado a esse espaço sociofísico, analisam as autoras, acompanhadas por outros estudiosos do tema ${ }^{21,22}$, há um sistema psíquico. Ambos interagem entre si e se potencializam. Tomando o Rio de Janeiro como um ecossistema, pode-se dizer que o município tem uma história, uma configuração espacial e uma cultura que influenciam nas várias expressões de violência que levam à morte, como as que são tratadas aqui.

\section{Método}

Foi realizado um estudo quantitativo descritivo, do tipo transversal, em que foram analisadas as mortes classificadas como decorrentes de agressões intencionais contra terceiros ou por letalidade violenta, notificadas à Polícia Civil do Estado do Rio de Janeiro (PCERJ) em 2015 e investigadas pelo sistema de segurança pública do estado. Segundo Aragã $0^{23}$, estudos transversais possibilitam o primeiro momento de análise de uma associação. Identificados os desfechos existentes, é possível enumerar fatores associados em diferentes graus. Da razão entre as diversas prevalências entre expostos e não expostos, extrai-se a medida de associação entre ambos, ou "razão de prevalências" (RP). É o que foi feito.

O cenário do estudo é o município do Rio de Janeiro, que segundo o Censo Demográfico de 2010, à época, tinha 6.320 .446 habitantes, distribuídos em um perímetro $1.200,177 \mathrm{~km}^{2}$ e com densidade demográfica de 5.265,82 habitantes/ $\mathrm{km}^{2}$. Para 2015, estimou-se uma população de 6.550.746 habitantes, 3.360.629 do sexo femini- 
no $(52,9 \%)$ e 2.959 .817 homens $(47,1 \%)$, com o seguinte perfil etário: $26,75 \%$ com até 19 anos; $16,78 \%$ entre 20 e 29 anos; 29,58\% entre 30 e 49 e $26,89 \%$ com 50 anos ou mais. Em 2010, a expectativa de vida ao nascer era de 75,69 anos no município. A divisão por raça/cor apresentava a seguinte distribuição: $51,2 \%$ das pessoas de cor branca, $11,5 \%$ de cor preta e $36,5 \%$ de cor parda. A taxa de homicídio para o município aquele ano foi de 18,5/100.000 habitantes.

As informações sobre as circunstâncias das mortes por letalidade violenta foram coletadas no banco da PCERJ, onde se concentram os dados de registros de ocorrência. Esse banco é constituído por um sistema denominado ROWEB (registro de ocorrência por Internet), sendo acessível remotamente mediante prévia autorização e concessão de senha para consulta. Não tem a funcionalidade de inserção, alteração ou retirada de dados, pois sua finalidade é meramente consultiva. As informações constantes no ROWEB são inseridas por meio de um "sistema de controle operacional" (SCO). Esse sim de acesso restrito aos agentes da instituição que elaboram os "registros de ocorrência" e o processo de investigações. Todo crime comunicado em uma Delegacia de Polícia do Estado do Rio de Janeiro enseja a lavratura de um registro de ocorrência ( $\mathrm{RO})$, ao qual é atribuído um número exclusivo que o acompanha até o fim da investigação. O sistema ROWEB oferece diversas opções de filtros para buscas, algumas delas foram escolhidas para serem utilizadas na pesquisa que deu origem a este artigo, a fim de melhor exprimir os dados acerca da letalidade violenta.

A análise consistiu na leitura, um por um, dos 1.562 registros de ocorrência classificados pelo título "letalidade violenta", e se referem a "latrocínios", "lesões corporais seguidas de morte", "homicídios dolosos" e "homicídios provenientes de oposição à intervenção policial” registradas em 2015. Do total, as três primeiras subclassificações analisadas neste artigo somaram 1.255 crimes. Os documentos foram classificados por delitos, segundo o ordenamento jurídico em que estavam inseridos. Focalizou-se o autor do crime, mas garantiu-se o anonimato das pessoas envolvidas e evitou-se retratar situações que possibilitassem o reconhecimento dos envolvidos nos crimes como autor ou vítima. As variáveis que traçam o perfil dos agressores foram: sexo, idade no ano da agressão letal, ocupação/profissão, grau de escolaridade e cor/raça. Considerou-se ainda a variável "relação prévia" do agressor com a vítima.

Os dados foram analisados por meio de medidas de tendência central e variabilidade para os desfechos quantitativos, e por frequências relativas para os desfechos categóricos. Para a categorização da idade, utilizou-se o padrão adotado pelo IBGE: até 19 anos; 20-29 anos; 30-39 anos; 40-49 anos; e 50 anos ou mais. Em relação às variáveis categóricas, foram utilizadas tabelas de agrupamento simples.

O campo "profissão", apesar de contemplar múltiplas possibilidades, foi tabulado com a exposição de todas as variáveis apresentadas nos registros, além da opção “outros” que existe no sistema para inserção de dados sem classificação descrita no banco. Analisou-se a variável: "relacionamento prévio" entre autor e vítima, com possibilidade de resposta positiva, negativa ou ignorada. Buscou-se identificar também a motivação do homicídio. O perfil dos autores de determinados tipos de mortes guarda similaridades, o que possibilita sua representatividade em relação a outros anos e à realidade social conflituosa do município do Rio de Janeiro.

Foram feitas análises bidimensionais entre duas ou mais variáveis. Em algumas situações, usaram-se dois (ou mais) conjuntos de dados provenientes da observação da mesma variável. Houve situações em que as duas eram qualitativas ou quantitativas e casos em que uma variável era qualitativa e a outra quantitativa.

Empregou-se um modelo de regressão logística para investigar o perfil dos autores de mortes intencionais, usando-se a transformação do logito (logaritmo neperiano do odds) para evitar que a função assumisse valores negativos. $\mathrm{Na}$ análise de regressão logística, a variável dependente (resposta) é uma aleatória dicotômica que assume o valor 1 se o evento de interesse ocorre, ou $0 \mathrm{em}$ caso contrário.

Além das informações recolhidas dos RO, outras foram buscadas no campo denominado "dinâmica do fato", presente nas fichas de registro, que consiste na breve descrição dos acontecimentos investigados feita pelo policial responsável pela confecção do RO. Dela constam: dia, hora, local e um resumo das circunstâncias do crime. Esses dados são fundamentais para que o investigador compreenda o contexto em que se deu a morte. Essa leitura contribuiu muito para a alimentação de duas outras variáveis: "relacionamento prévio entre autor e vítima" e, em caso positivo, o "tipo de relacionamento". Nas situações em que havia mais de um autor para a mesma morte, decidiuse que o vínculo de maior proximidade prevaleceria e se estenderia para os demais.

Sobre o tipo de vínculo, contexto, ou circunstância de causa da agressão, as informações 
foram estratificadas, como estratégia para melhor agrupar por semelhança e proximidade de acordo com o tipo de relação verificada na leitura da dinâmica das ocorrências. Entre essas, figuraram algumas autoexplicativas, como "familiar" e "cônjuge"; e outras demandaram esclarecimentos. Nos casos em que o autor e a vítima se conheciam previamente, e que o perfil não estava inserido em alguma outra classificação, usou-se o termo "conhecido". Outros dois vocábulos independentes, "tráfico" e "milícia", foram utilizados para categorizar os autores de homicídio com motivações vinculadas a essas duas atividades ilegais muito presentes na realidade do município do Rio de Janeiro e costumam se originar de divergências internas dentro dos grupos, disputas com rivais e homicídios consumados, inclusive para demonstração de força e legitimação de território. A circunstância da agressão causadora da morte se fez presente, mesmo em situações em que não havia vínculo entre autor e vítima ou em que não foi possível determiná-lo. Por exemplo, houve morte em que o desenlace não demonstrou ter sido provocado pelo tráfico, mas por presunção da vítima pertencer a uma facção rival. Nessa situação, a circunstância foi classificada como vinculada ao tráfico de drogas. Esse desfecho se orientou pela mesma lógica da variável "relacionamento prévio", como já explicado.

\section{Resultados}

A Tabela 1 mostra os dados demográficos dos autores de letalidade violenta - menos as mortes provenientes de resistência policial no município do Rio de Janeiro em 2015 - segundo sexo, faixa etária, raça/cor, escolaridade e proximidade de relação entre autores e vítimas. As diferenciações internas entre todas essas variáveis para cada tipo de crime, inclusive para o nível de elucidação, estão descritas na Tabela 1.

É relevante, inicialmente, mostrar o baixo índice elucidativo do perfil dos autores de todos os tipos de crimes: das 1.255 mortes violentas ocorridas, apenas 246 tiveram pelo menos um autor qualificado, o que representa cerca de $20 \%$ de esclarecimento dos casos, gerando um total de 391 realmente caracterizados. Dos 1.200 homicídios dolosos, apenas 217 (aproximadamente 18\%), chegaram à identificação de ao menos um agressor, totalizando 340 qualificados. Das 44 mortes por latrocínio, em 25 dos casos (57\%) os autores foram reconhecidos, gerando 46 autores identificados. E dos 11 óbitos por lesões corporais se- guidas de mortes, somente quatro tiveram pelo menos um autor qualificado (36\%), com cinco autores em números totais.

A seguir, o perfil dos agressores segundo as variáveis estudadas.

Sexo e cor - O perfil dos agressores aponta uma supremacia masculina: 367 homens $(94 \%)$ e 24 mulheres (6\%). Há predominância de autores de cor parda $(165-42 \%)$, seguida dos de cor branca $(118-30 \%)$ e 92 (24\%) de cor preta. Dezesseis pessoas (4\%) não tiveram essa informação registrada. Quando se considera no modelo a representação populacional por cor/raça utilizada pelo IBGE, que junta pretos e pardos, esse grupo soma 257 agressores, $66 \%$ do total. Tanto no que se refere ao sexo quanto à cor/raça, o mesmo perfil de autores e vítimas é constatado, sendo que apenas sobre as vítimas o assunto está vastamente documentado.

Faixa etária - O grupo de 20-29 anos concentra quase metade do total dos agressores, 185 (47\%). Esse é seguido pelo de 30-39 com 103 (26\%), acompanhado pelo segmento de 40-49 anos, com 51 pessoas (13\%). Os demais 52 autores (14\%) se diluem nas outras faixas etárias: 29 (8\%) com até 19 anos; 12 (3\%) entre 50-59 anos; nove $(2 \%)$ com 60 anos ou mais. Em dois casos (1\%) a idade não foi especificada. A preponderância de agressores com idade entre 20 e 29 anos é exatamente a mesma em que há maior número de vítimas, conforme se observa na literatura.

Escolaridade - A análise da escolaridade mostra que 159 agressores tinham até o primeiro grau, dos quais apenas 43 o haviam completado. Com segundo grau foram 82 pessoas, mas só $47 \mathrm{o}$ haviam terminado. Com terceiro grau foram encontrados 14 agressores, seis com formação completa e oito com incompleta. É importante ressaltar que, em $35 \%$ dos registros dos 391 agressores, essa variável não foi preenchida. Tal lacuna se deve a problemas de alimentação do banco sobre homicídios em geral, impossibilidade de verificação desse quesito junto ao autor, ou recusa do agressor em prestar tal informação.

Ocupação - Para quase metade dos agressores $(180$ - 46\%) não havia informação sobre "ocupação" nos RO. Quando se alia essa primeira opção à "não especificada/outros" esse número sobe para um total de 243 (62\%). Apenas 38\% dos agressores foram qualificados quanto às atividades que exerciam. Dois problemas: a maioria deles não estava vinculada a atividades produtivas regulares e os policiais se preocupam pouco em esclarecer esse item nos RO. A pouca clareza das informações sobre "ocupação" sugere que no 
Tabela 1. Dados sociodemográficos dos autores de letalidade violenta esclarecidas no município do Rio de Janeiro em 2015.

\begin{tabular}{|c|c|c|c|c|c|c|c|}
\hline Categoria & $\begin{array}{l}\text { Quantidade } \\
\text { de casos } \\
\text { com } \\
\text { autoria }\end{array}$ & $\begin{array}{c}\text { Quantidade } \\
\text { de autores } \\
\text { identificados }\end{array}$ & Sexo & $\begin{array}{l}\text { Faixa } \\
\text { etária }\end{array}$ & Cor/raça & Escolaridade & $\begin{array}{c}\text { Relação } \\
\text { prévia } \\
(\mathrm{S} / \mathrm{N})\end{array}$ \\
\hline $\begin{array}{l}\text { Lesão } \\
\text { corporal } \\
\text { seguida de } \\
\text { morte }\end{array}$ & 04 & 05 & Masculino-80\% & $\begin{array}{c}20-29 \\
\text { anos-40\% } \\
30-39 \\
\text { anos- } 40 \%\end{array}$ & $\begin{array}{c}\text { Parda-40\% } \\
\text { Branca-40\% }\end{array}$ & $\begin{array}{l}\text { Ens.Méd.Comp.-60\% } \\
\text { Ens.Fun.Comp.-40\% }\end{array}$ & $\begin{array}{l}\text { Sim- } \\
80 \%\end{array}$ \\
\hline Latrocínio & 25 & 46 & Masculino-100\% & $\begin{array}{c}20-29 \\
\text { anos-59\% } \\
10 / 19 \\
\text { anos-17\% }\end{array}$ & $\begin{array}{l}\text { Pardo-37\% } \\
\text { Negra-28\% }\end{array}$ & $\begin{array}{c}\text { Ens.Fund.Inc.-39\% } \\
\text { Não Especificada-39\% }\end{array}$ & $\begin{array}{l}\text { Não- } \\
96 \%\end{array}$ \\
\hline $\begin{array}{l}\text { Homicídio } \\
\text { doloso }\end{array}$ & 217 & 340 & Masculino-93\% & $\begin{array}{c}20-29 \\
\text { anos-46\% } \\
30-39 \\
\text { anos- } 28 \%\end{array}$ & $\begin{array}{l}\text { Pardo-43\% } \\
\text { Branca-30\% }\end{array}$ & $\begin{array}{c}\text { Não Especificada-35\% } \\
\text { Ens.Fund.Inc.-28\% }\end{array}$ & $\begin{array}{l}\text { Sim- } \\
72 \%\end{array}$ \\
\hline Total geral & 246 & 391 & Masculino-94\% & $\begin{array}{c}20-29 \\
\text { anos- } 47 \%\end{array}$ & Parda- $42 \%$ & Ens.Fund.Inc.-30\% & $\begin{array}{l}\text { Sim- } \\
75 \%\end{array}$ \\
\hline
\end{tabular}

Fonte: ROWEB/PCERJ.

termo "outros" se escondem, além de trabalhos de "biscate", atividades ilegais, como tráfico de drogas e participação em milícias. E é importante observar que, dos 38\% dos agressores com ocupação identificada, foram apontadas 33 ocupações: "pedreiro/ajudante (X\%?)", “autônomo" (5\%); "comerciário" (4\%); "policiais militares" (4\%); “estudantes" (4\%); e "do lar" (1\%). Deve-se esclarecer que a autoria de policiais como agressores, aqui assinalada, refere-se aos que cometeram crimes não classificados como "autos de resistência". Por isso foram enquadrados em outras categorias de autores de letalidade violenta.

Tipologia das agressões - Este segmento da análise conjuga três categorias: "roubo seguido de morte", "lesão corporal seguida de morte" e "homicídio doloso". A última comporta uma variedade de condutas e um sistema de subclassificação das mortes: (1) pelo meio empregado para causá-la (arma branca; arma de fogo; asfixia; paulada; e queimadura); (2) quem é a vítima no caso do feminicídio; e (3) "outros", em caso de não enquadramento nas tipificações anteriores. Foi possível estabelecer a média de autores por vítima de acordo com o tipo de agressão, o que contribui para compreender por que alguns tipos apresentam número maior de agressores qualificados.

O Gráfico 1 demonstra que a média de agressores por vítima chega a 2,3 no caso do homicídio por paulada, em que foram qualificados nove agressores para quatro mortos. Em seguida vem o latrocínio, com 46 agressores e 26 vítimas (média de 1,8), e o homicídio por arma de fogo, com 156 autores e 99 vítimas (média de 1,6). A média geral foi de 1,5, com 391 autores qualificados e 266 vítimas.

Foi possível analisar também a chance de existência de "relacionamento prévio" e "tipo de relação" entre agressor e vítima. Algumas modalidades de crime são características de pessoas que convivem proximamente. Essas duas variáveis foram analisadas em conjunto, graças ao nexo que adquirem para a compreensão dos homicídios intencionais. Foram considerados os números de ocorrências (246), do total de vítimas (265) e dos autores (391). Verificou-se que em 166 (68\%) casos, que correspondem a 246 registros, havia relação prévia entre ambos. Não foi possível determinar a existência ou não de vínculo anterior em dez dos eventos (4\%).

Os resultados ressaltam que, em alguns tipos de agressão, quase todas as ocorrências aconteceram entre pessoas próximas: com uso de arma branca foram 43 em 44; por asfixia, dez em dez; por paulada, quatro em quatro; por lesão corporal seguida de morte, três em quatro; por queimadura, uma em uma; e por feminicídio, também uma em uma. Observação necessária é que a categoria "feminicídio" está sub representada porque a Lei Federal no 13.104, de 9 de março de 2015, que trata do feminicídio e da sua notifica- 
ção específica, acabava de ser aprovada no Congresso Nacional quando se realizou a pesquisa do material para este trabalho. Isso explica por que houve apenas um caso captado pelo ROWEB.

Em 52 dos 83 registros de homicídios por arma de fogo havia relações prévias entre autor e vítima. Apesar de apresentar uma proporção menor desse quesito quando comparado com as tipologias anteriores, é relevante o fato de que em $2 / 3$ dos casos autor e vítima se conhecessem. A opção "outros" também apresentou a relevante existência de relacionamento prévio entre agressor e agredido (53 de 76). A categoria "roubo seguido de morte" destoa dessa dinâmica, em virtude de suas características peculiares. Em apenas um dos 25 registros constatou-se relacionamento prévio. Nos RO em que não foi possível confirmar ou refutar a existência de vínculo, a distribuição se deu da seguinte forma: quatro homicídios por arma de fogo; um roubo seguido de morte; e cinco homicídios classificados como "outros".

Homicídios por arma de fogo - Em virtude de ter concentrado o maior número de registros, de vítimas e de autores qualificados, respectivamente 83, 99 e 156, entendeu-se como relevante verificar o tipo de vínculo entre autor e vítima para melhor compreender o perfil dos agressores (Tabela 2).

A análise conjunta das duas variáveis, homicídios por arma de fogo e tipo de relação, revela que 81 autores qualificados (52\%) mataram usando arma de fogo por envolvimento com tráfico de drogas, em várias situações: acerto in- terno de contas, disputa com grupos rivais por domínio de territórios, cobranças de dívidas e demonstração de força, corroborando os achados de Dirk e Moura ${ }^{12}$. Os autores vinculados à milícia (16) aparecem em terceiro lugar e representam $10 \%$ do total, em circunstâncias similares às que motivaram os assassinatos por tráfico de drogas. Portanto, quando se juntam essas duas atividades relacionadas às organizações ilegais, encontra-se quase uma centena de autores qualificados (97), representando cerca de $2 / 3$ do total dos que cometeram homicídio com uso de armas de fogo.

Chama atenção o elevado número de agressores nas mortes vinculadas ao tráfico de drogas: há situações em que são registrados seis, sete ou até mesmo oito autores para apenas um caso $^{5}$.

Tabela 2. Distribuição de homicídio por arma de fogo segundo o tipo de relação entre autor e vítima.

\begin{tabular}{lcc}
\hline Tipo de relação & Frequência & $\begin{array}{c}\text { Frequência } \\
\text { relativa }\end{array}$ \\
\hline Tráfico & 81 & $52 \%$ \\
Conhecido & 22 & $15 \%$ \\
Milícia & 16 & $10 \%$ \\
Cônjuge & 5 & $3 \%$ \\
Atividade policial & 9 & $6 \%$ \\
Desconhecido & 11 & $7 \%$ \\
Familiar & 7 & $4 \%$ \\
Não especificada & 5 & $3 \%$ \\
Total geral & 156 & $100 \%$ \\
\hline
\end{tabular}

Fonte: ROWEB/PCERJ.

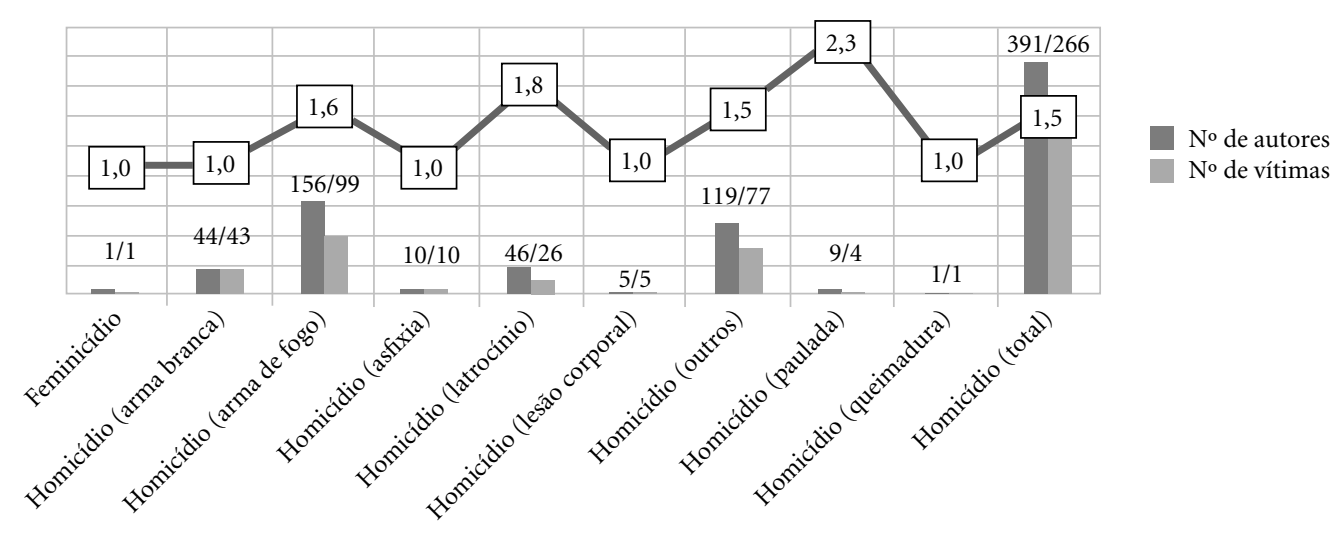

Gráfico 1. Relação entre números de autores e de vítimas segundo a tipologia da agressão, Rio de Janeiro, 2015. 
Essa atribuição de um mesmo ato a várias pessoas foi verificada em muitos casos envolvendo milícia e tráfico de drogas, e pode ser explicada pela dificuldade da investigação em definir a participação efetiva de cada autor na agressão. Por esse motivo, os policiais que notificam costumam utilizar o recurso de responsabilizar também as lideranças locais das quadrilhas, por entenderem que qualquer fato dessa natureza só ocorre com conhecimento, anuência e a participação direta ou indireta deles, mesmo que muitas vezes não estejam presentes fisicamente no momento das agressões, conforme mencionado por Araruna ${ }^{13}$.

A arma de fogo, tão comum nos embates de traficantes e milicianos, também se mostrou relevante na configuração da violência interpessoal: foram utilizadas para agredir e matar por 22 autores classificados como conhecidos (15\% do total), além de mais sete classificados como familiares e cinco como cônjuges, totalizando 34 agressores $(22 \%)$, só ficando atrás das mortes em que a especificação do vínculo foi gerada pela ligação com atividades de tráfico e milícia. Os demais tipos de relação responderam por cerca de $16 \%$ do total de mortes por arma de fogo: desconhecidos, 11 (7\%); atividade policial, nove (6\%); e não especificado, cinco (3\%).

Os homicídios por relação de proximidade expõem a dificuldade de solução de conflitos e divergências entre pessoas próximas (conhecidos, familiares e cônjuges), direcionando os desfechos para tragédias evitáveis e com frequência por motivos fúteis. $\mathrm{O}$ estudo mostra que, infelizmente, o acesso às armas na sociedade fluminense não está restrito apenas aos agentes de segurança pública em serviço ou em horário de folga e aos envolvidos com atividades criminosas como o tráfico de drogas e a milícia. A pesquisa reforça a tese de que, além da relação direta entre o acesso a esses meios por grupos criminosos e as mortes violentas, esse recurso também é adotado, em larga medida, na solução de conflitos do dia a dia por cidadãos que portam armas, tendo desfechos fatais.

\section{Discussão e considerações finais}

Buscou-se aprofundar a quantidade, a especificidade e as características dos autores de letalidade violenta intencional no município do Rio de Janeiro. É importante dizer que a relevância deste trabalho está em focalizar os agressores, um tema muito pouco estudado, uma vez que a maioria das pesquisas se interessa pelas vítimas.
O perfil dos autores de letalidade violenta esclarecida no município em 2015 foi formado predominantemente por homens (94\%), com idade média de 30,7 anos, havendo concentração nos grupos de 20-29 e 30-39 (essas faixas etárias, mais a dos jovens com menos de 18 anos, responderam por $81 \%$ dos agressores), com baixa escolaridade e altos registros de desocupação ou subocupação e inserção em atividades e práticas criminosas.

Suas características guardam similaridade com o perfil das vítimas de mortes violentas no mesmo espaço urbano. Essa primeira frase pode soar óbvia. No entanto, encontrar as características semelhantes na díade agressor/vítima é resultado de um estudo minucioso de cada ficha criminal dos homicídios de 2015, o que permitiu demonstrar essa afirmativa. A hipótese que acompanhou o trabalho é a de que grupos de perfil semelhante se confrontam e se sacrificam por domínio de território, armas, poder e presença quando militam no mercado ilegal ${ }^{4,5-21}$. No entanto, o estudo ressalta que eles não se matam apenas entre si. As mortes por motivos fúteis ou interpessoais (39\% do total) demonstram a disseminação de um ambiente conflituoso na sociedade, fomentado por armas entre civis, responsáveis por $22 \%$ das mortes violentas ${ }^{5}$. Os vários tipos de violência se potencializam mutuamente e ambientes conflagrados são espaços de vivências e práticas agressivas tanto no seio das famílias e nas relações conjugais como no trabalho, nas vizinhanças e na sociedade $\mathrm{e}^{3,5,18-25}$.

O Rio de Janeiro é um município violento. Mais do que isso, tem fama de violento. Embora não seja o que apresente as maiores taxas de homicídio do país, o temor de visitá-lo, de viver aqui e de estabelecer negócios em seu território o acompanha. Portanto, como ressaltam Minayo e Constantino $^{19}$, é preciso fugir da ideia da criminalização apenas de pessoas ditas desviantes. Pois em contextos de intensa percepção de violência, encontra-se uma comunidade com laços frouxos e fragmentados, com dificuldades para concretizar objetivos comuns e resolver problemas como pobreza, deterioração territorial, excessiva mobilidade residencial e heterogeneidade étnica. É como se o fatalismo marcasse uma espécie de identidade local criminógena, frequentemente assumida pela sociedade, repercutida pela mídia e usada politicamente pelas autoridades locais, que costumam tentar a mágica da transformação social por meio da polícia ${ }^{5,20-22}$.

Destacam-se os baixos percentuais de elucidação de autores dos crimes, além de se constatar 
o preenchimento insuficiente dos RO, o que dificulta uma análise mais fidedigna da dinâmica dos homicídios e contribui para a impunidade, um dos grandes problemas de segurança pública do Rio de Janeiro. Cabe ressaltar, principalmente, a pouca atenção dada ao item "ocupação" nos registros: 180 (46\% do total) dos registros de ocorrência não a especificaram, o que não é apenas um problema da área de segurança pública, pois ocorre também nos sistemas de informação em saúde. No entanto, apesar das falhas, foi possível observar que a maioria dos agressores para os quais a atividade foi anotada - tanto os que exerciam atividades no tráfico e na milícia como os que cometeram homicídio por roubo ou por razões interpessoais - são pessoas desempregadas ou que atuam na informalidade. Esse resultado sugere que é nesse grupo que a milícia e o tráfico de drogas recrutam seus trabalhadores $^{5,11-13,18,21,22,24-26}$, visto que as atividades que desenvolvem dificultam a participação simultânea em alguma ocupação produtiva legal.

Em relação à variável cor/raça, observa-se grande concentração no grupo de "pardos e pretos", com $66 \%$ dos autores qualificados, contra $31 \%$ registrados como brancos e $3 \%$ sem informação, o que se assemelha ao perfil das vítimas. Ou seja, a população negra não figura nesse cenário de violência local somente como vítima. Ela está também significativamente representada como agressora, sobretudo pela participação ou proximidade com grupos envolvidos em atividades ilegais. Essa é uma conclusão muito delicada porque pode sugerir uma criminalização dos negros, já tão vulnerabilizados na sociedade brasileira. Por isso, o dado precisa ser contextualizado historicamente, entendido a partir das condições de desigualdade e degradação social em que muitos vivem e das poucas oportunidades que encontram numa sociedade competitiva ao extremo $0^{5,19}$.

Os dados sobre escolaridade ressaltam que a maior concentração de autoria está nos grupos com menor grau de instrução. Esse fato permite pelo menos duas reflexões: menor nível de escolaridade pode significar mais dificuldade de solução de conflitos de forma pacíficaa ${ }^{1,5}$. Em segundo lugar, facilita a inserção dos agressores em grupos vinculados à milícia e ao tráfico de drogas ${ }^{3,4,19-22,24}$. Ao contrário, encontrou-se vinculação direta entre aumento do grau de instrução com a redução da chance de ser qualificado como autor de homicídio. A elevação dos níveis escolares e de formação profissional influi tanto na maior capacidade de resolução de conflitos como nas possibilidades de conseguir emprego formal ${ }^{1}$.
A existência de vínculo de proximidade anterior à agressão causadora da morte também é um ponto forte do estudo. Por meio de uma variável específica, demonstrou-se que $64 \%$ dos autores qualificados nas três categorias de crime já possuíam algum tipo de relação com suas vítimas, seja vínculo interpessoal ou em decorrência de atividade criminosa continuada na milícia e no tráfico de drogas. No caso dos laços pessoais, o percentual foi de $39 \%$, incluindo familiares (6\%), conhecidos (24\%) e cônjuges (9\%). O que mostra um adensamento dos crimes em determinados espaços sociais, uma espécie de aculturação pela violência, e neles, um ambiente intensamente conflituoso ${ }^{2,5}$.

Um aspecto relevante do trabalho, mas não inédito, é a demonstração das elevadas proporções de homicídios com uso de armas de fogo: $52 \%$ daqueles vinculados ao tráfico de drogas, que junto com a milícia somam $62 \%$. A esses se acrescentam os $22 \%$ por roubo e violência interpessoal. As mortes cometidas por milicianos, segundo Cano e colaboradores ${ }^{9}$, certamente são em número muito maior do que as registradas, pois eles atuam de forma discreta, desaparecendo com desafetos.

As constatações acima não comungam com a ideia de determinismo social, seja em relação aos indivíduos ou ao município. Embora sejam reais as condições adversas da grande maioria das pessoas que entram para grupos criminosos, o cotidiano carioca está repleto de exemplos de indivíduos pobres, que moram em áreas dominadas por traficantes e milícias, que estudam, trabalham e conseguem se projetar. Como lembra Sartre em sua última entrevista ao Le Nouvel Observateur, em fevereiro de 1980: "Cada um é sempre responsável pelo que fizeram dele [...]. Essa é a definição que eu daria de liberdade: este pequeno movimento que faz de um ser social totalmente condicionado, uma pessoa que não constitui a totalidade do que recebeu de seu condicionamento. Que fez de Jean Génet um poeta, ainda que ele tenha sido rigorosamente condicionado para ser um ladrão" (p. 3$)^{27}$.

De forma geral, é possível dizer que autores e vítimas não são necessariamente vinculados de modo prévio à criminalidade, ao tráfico de drogas e à milícia. No entanto, essas atividades têm grande peso nos resultados aqui verificados, em virtude dos recursos de coerção e legitimação que traficantes e milicianos detêm. Na convivência de parte da população em ambientes degradados socialmente e carentes de oportunidades sociais, costuma predominar uma forma de comunica- 
ção violenta que contribui para que situações de desavenças ou diferenças interpessoais culminem em homicídio. Existe, como dizem Kubrin e colaboradores ${ }^{22}$, um efeito de reciprocidade entre o comportamento do sistema social e o dos sujeitos: medo e insegurança geram déficit de coesão e de participação e reduzem a vontade das pessoas de se engajarem no controle social formal ou informal. Cria-se, assim, uma espécie de cinismo em relação às normas legais. Nesse vácuo de controle social, os delinquentes costumam assumir o poder e usar sanções cruéis aos que os desrespeitam, criando uma subcultura do crime ${ }^{21}$.

Outro ponto a comentar é a influência do ambiente externo sobre o sistema social. Os efeitos das políticas macroeconômicas e macrossociais influenciam as taxas de criminalidade e de informalidade em localidades violentas. Existe evidência empírica de que o desinvestimento em determinado lugar (caso do Rio de Janeiro) redunda em aumento de desempregados e pobres, instabilidade demográfica, incremento de residências precárias e ocupações informais. Criase um círculo vicioso: fogem as oportunidades econômicas e de turismo e cresce o isolamento territorial e social dos moradores ${ }^{21,22,24}$.
Por fim, é importante refletir sobre o papel de intervenções sociais para provocar mudanças na redução das taxas de homicídios ${ }^{28}$. Não basta prender os agressores. A história mundial está repleta de exemplos do que dá certo ${ }^{1,26}$. Há casos de sucesso no Brasil também ${ }^{9,25,29}$.Um dos mais consistentes é a intervenção do Programa Fica Vivo, do estado de Minas Gerais, combinando ações preventivas e repressivas em áreas com alta concentração de homicídios. Esse programa inclui participação comunitária e suporte social para solução das questões locais e foco nos jovens tanto para ações sociais como para ações repressivas por meio do sistema policial e judicial. A avaliação de impacto realizada por Peixoto e colaboradores $^{29}$ indica que o Fica Vivo conseguiu reduzir a criminalidade e os homicídios em todas as seis áreas onde foi implementado, demonstrando que a condição para superação de um ambiente de violência depende do investimento em propostas de cunho social e político e precisam ser personalizadas, combinadas com ações repressivas por parte do Estado. O Rio de Janeiro precisa investir corretamente!

\section{Colaboradores}

RSA Marins trabalhou na descrição dos dados e na análise estatística. MCS Minayo analisou o material e ficou responsável pela elaboração final do texto. 


\section{Referências}

1. Chesnais JC. Histoire de la violence en Occident. Paris: Editorial Pluriel; 1981.

2. Minayo MCS, Franco S. Violence and health. Oxford Encyclopedia of Research. Available from: http:// publichealth.oxfordre.com/view/10.1093/acrefore/9780190632366.001.0001/acrefore-97801906 32366-e-32?rskey=RbrFm8\&result $=1$

3. Minayo MCS, Assis SG, organizadoras. Novas e velhas faces da violência no século XXI. Rio de Janeiro: Editora Fiocruz; 2018.

4. Minayo MCS, Souza ER, organizadoras. Violência sob o olhar da saúde: a infrapolítica da contemporaneidade brasileira. Rio de Janeiro: Editora Fiocruz; 2003.

5. Mariz RSA. Homicídio no município do Rio de Janeiro: quem mata? [dissertação]. Rio de Janeiro: Escola Nacional de Saúde Pública; 2019.

6. Instituto de Segurança Pública do Rio de Janeiro. Dados de homicídios no estado por capital, baixada e interior [site da Internet]; 2017. [acessado 2017 Ago 18]. Disponível em: https://www.isp.rj.gov.br:4431/ default.asp

7. Instituto de Segurança Pública do Rio de Janeiro. Dados de homicídios no estado por capital, baixada e interior [site da Internet]; 2018. [acessado 2018 Ago 18]. Disponível em: https://www.isp.rj.gov.br:4431/ default.asp

8. Instituto de Segurança Pública do Rio de Janeiro. Dados de homicídios no estado por capital, baixada e interior [site da Internet]; 2019. [acessado 2019 Ago 18]. Disponível em: https://www.isp.rj.gov.br:4431/ default.asp

9. Henriques R, Ramos S. UPP Social: ações sociais para consolidação da pacificação do Rio - a hora da virada. In: Urani A, Gambiagi F, organizadores. Rio: a hora da virada. Rio de Janeiro: Campus/Elsevier; 2010. p.242254.

10. Ratton JL, Laudelin J. Construction and desconstruction of a homicide reduction policy: the case of pact for life in Pernambuco, Brazil. International Journal of Criminology and Sociology 2018; 7:173-183.

11. Cano I, Duarte T. No sapatinho: a evolução das milícias no Rio de Janeiro. Rio de Janeiro: Fundação Heinrich Böll; 2012.

12. Dirk R, Moura L. As motivações nos casos de letalidade violenta da Região Metropolitana do Rio de Janeiro. Cadernos de Segurança Pública 2017; 9(8):1-10.

13. Araruna RB. A teoria do domínio do fato e sua adoção no Brasil. Cadernos do Ministério Público do Estado do Ceará [periódico na Internet]; 2006. [acessado 2019 Nov 26]. Disponível em: http://www.mpsp. mp.br/portal/page/portal/documentacao_e_divulgacao/doc_biblioteca/bibli_servicos_produtos/ bibli_informativo/bibli_inf_2006/Cad-MP-CE_ v.01_n.01_t.02.04.pdf

14. Souza ER. Homicídios na América Latina: por uma busca de abordagens extensiva e compreensiva. Cien Saude Colet 2012; 17(12):3156.
15. Murray J, Cerqueira DRC, Kahn T. Crime and violence in Brazil: systematic review of time trends, prevalence rates and risk factors. Aggression and Violent Behavior 2013; 18(5):471-483.

16. Misse M. Crime, sujeito e sujeição criminal: aspectos de uma contribuição analítica sobre a categoria "bandido". Lua Nova 2010; 79:15-38.

17. Lee LK, Fleegler EW, Farrell C, Avakame E, Srinivasan S, Hemenway D, Monuteaux MC. Firearm laws and firearm homicides: a systematic review. JAMA Intern Med 2017; 177(1):106-119.

18. Zaluar A. Teleguiados e chefes: juventude e crime. Rio de Janeiro: Revan; 1994.

19. Souza ER. Masculinidade e violência no Brasil: contribuições para a reflexão no campo da saúde. Cien Saude Colet 2005; 10(1):59-70.

20. Duque LF, Montoya NE, Restrepo A. Aggressors and resilient youths in Medellin, Colombia: the need for a paradigm shift in order to overcome violence. Cad Saude Publica 2013; 29(11):2208-2216.

21. Minayo MCS, Constantino P. Visão ecossistêmica do homicídio. Cien Saude Colet 2012; 17(12):3269-3278.

22. Taylor R. Fear of crime, social ties and collective efficacy. Justice Quarterly 2002; 19:773-795.

23. Aragão J. Introdução aos estudos quantitativos utilizados em pesquisas científicas. Práxis 2011;3(6): 2532.

24. Kubrin C, Weitzer R. Reliatory homicide: concentrated disadvantage and neighborhood culture. Social Problems 2003; 50:157-180.

25. Peres MFT, Vicentin D, Lima RS, Souza ER, Carda M, Cardia N, Adorno S. Queda dos homicídios em São Paulo: uma análise descritiva. Rev Panam Salud Publica 2011;29(1):17-26.

26. Wieviorka MO. La violence aujourd'hui. Cien Saude Colet 2006; 11(2):310-315.

27. Sartre JP. Última entrevista a Benny Lévy. Le Nouvel Observateur. Paris: 1980.

28. Minayo MCS, Souza ER. É possível prevenir a violência? Reflexões a partir do campo da saúde pública. Cien Saude Colet 1999; 4(1):7-24.

29. Peixoto BT, Andrade MV, Azevedo JP. Prevenção e controle de homicídios: uma avaliação de impacto no Brasil. Belo Horizonte: UFMG, Cedeplar; 2008.

\footnotetext{
Artigo apresentado em 06/03/2020

Aprovado em 09/03/2020

Versão final apresentada em 11/03/2020

Editores-chefes: Romeu Gomes, Antônio Augusto Moura da Silva
} 